\title{
The EPICure study: maximal exercise and physical activity in school children born extremely preterm
}

\author{
Liam Welsh, ${ }^{1}$ Jane Kirkby, ${ }^{1}$ Sooky Lum, ${ }^{1}$ Dolf Odendaal, ${ }^{2}$ Neil Marlow, ${ }^{3}$ \\ Graham Derrick, ${ }^{2}$ Janet Stocks, ${ }^{1}$ for the EPICure Study Group
}

- Supplementary figures, tables and equations are published online only at http://thx.bmi. com/content/vol65/issue2

${ }^{1}$ Portex Unit: Respiratory Medicine and Physiology, UCL, Institute of Child Health, London, UK ${ }^{2}$ Cardiac Unit, Great Ormond Street Hospital for Children NHS Trust, London, UK ${ }^{3}$ School of Human Development, University of Nottingham, Nottingham, UK

Received 11 September 2008 Accepted 14 October 2009 Published Online First 8 December 2009

\section{ABSTRACT}

Rationale Evidence regarding exercise capacity and physical activity in children born extremely preterm (EP) is limited. Since survivors remain at high risk for developing bronchopulmonary dysplasia (BPD) and longterm pulmonary sequelae, reductions in exercise capacity and activity levels may be present.

Objectives To compare maximal exercise ventilation characteristics and physical activity levels at 11 years of age in children born EP ( $<25$ completed weeks gestation) with those of full-term controls.

Methods Participants performed spirometry, body plethysmography and gas transfer testing. A peak exercise test was performed on a cycle ergometer. Physical activity was monitored by accelerometry for 7 days.

Results Lung function and exercise results were obtained in 38 EP children (71\% prior BPD) and 38 controls. Those born EP had significantly lower Z-scores (mean (95\% Cl) of difference) for forced expiratory volume in $1 \mathrm{~s}\left(\mathrm{FEV}_{1} ;-1.74(-2.25\right.$ to -1.23$)$ and gas transfer $(-0.73(-1.31$ to -0.17$)$, and significantly greater Z-scores for residual volume (RV; 0.58 (0.10 to $1.10)$ ) and RV/total lung capacity (TLC; 0.74 (0.29 to 1.19)). EP birth was associated with a significant reduction in peak oxygen consumption. EP children employed greater breathing frequencies and lower tidal volumes during peak exercise. No differences were observed in physical activity between groups.

Conclusions The reduction in peak oxygen consumption in children born EP, and alterations in ventilatory adaptations during peak exercise were not explained by differences in physical activity, but probably reflects the long-term pathophysiological impact of EP birth.

\section{INTRODUCTION}

Over the past two decades, survival rates for infants born extremely preterm (EP; ie, <25 completed weeks gestational age (GA)) have increased dramatically. ${ }^{1}$ However, survivors remain at risk for development of bronchopulmonary dysplasia (BPD) and long-term pulmonary sequelae, with disrupted alveolar development reported in EP infants and those born small-for-gestational age. ${ }^{2}$ Despite this, our understanding of the consequences of preterm birth and any subsequent injury on life-long respiratory health is limited, and it remains unclear whether improved survival has been accompanied by increased impairment.

Several studies have focused on the exercise capacity of children born preterm, ${ }^{4-13}$ but many of these data were collected prior to the introduction of modern perinatal care including antenatal steroids and exogenous surfactant. Up to date and adequately powered evidence is therefore required, which relates to the new generation of surviving EP children. There is also limited information regarding specific ventilatory responses such as relative changes in tidal volume or respiratory rate during peak exercise among this group. ${ }^{8} 9$ Such characteristics may be important in terms of exercise efficiency and tolerance, and in providing further insight into the pathophysiology of lung development in this group.

Similarly, little is known about the physical activity habits of children born preterm. ${ }^{14}$ Given that up to $50 \%$ of children with prior BPD are reportedly affected by exercise-induced bronchoconstriction (EIB), ${ }^{15}$ reduced activity levels might be expected among preterm children. Any such inactivity may eventually lead to reductions in aerobic fitness, thereby increasing the likelihood of reaching ventilatory limitation at modest levels of exercise intensity. The typically unpleasant sensations of breathlessness associated with reaching such a limitation could act as a deterrent to exercise and initiate a self-limiting cycle of inactivity.

A better description of maximal exercise ventilation and physical activity habits among preterm children is required to determine whether deficits are present and whether such pursuits are indeed safe. Such information would further our knowledge with regard to long-term outcomes of preterm birth, and could ultimately lead to improvements in treatment and/or management with respect to physical conditioning programmes.

The primary aim of this study was to compare maximal exercise ventilation characteristics of children born EP with those of age-matched controls, to elucidate the influence of EP birth. Secondary aims were to better characterise physical activity habits among children born EP and to assess self-reported perceptions of exercise ability. We hypothesised that, when compared with full-term controls, children born EP would (1) have a reduced anaerobic threshold and peak oxygen consumption (peakVO 2 ); (2) demonstrate different exercise ventilation characteristics; (3) engage in less physical activity and; (4) have a reduced perception of exercise ability.

\section{METHODS \\ Participants}

The 'EPICure' study was designed to determine population-based data for children born at extremely low gestations. ${ }^{16}$ All children born at $<25$ completed weeks GA during 1995 in the UK and Republic of Ireland were identified and survivors 
recruited into a longitudinal follow-up study. ${ }^{16}$ Participants were initially seen at school between 10 and 11 years by a psychologist and paediatrician; assessments included spirometry and anthropometry. Classroom controls were selected on the basis of age, sex and ethnic group. Controls were ineligible if born preterm $(<37$ weeks GA), had been hospitalised for a respiratory complaint or had had pneumonia, tuberculosis (TB) or whooping cough. Asthma and atopy were not exclusion criteria. Index and control children whose parents gave written consent and who were living within reasonable travelling distance of London, were recruited. The recruitment process is summarised in the online supplement (OLS; figure E1) as are further comprehensive details on participants and methodology. Local research ethics committee approval was obtained.

\section{Anthropometry}

Height was recorded without shoes to the nearest $0.1 \mathrm{~cm}$ using a fixed stadiometer (Harpenden Stadiometer, Holtain Ltd, Dyfed, UK). Weight was measured in minimal clothing, without shoes, to the nearest $0.1 \mathrm{~kg}$ using digital scales (Tanita BWB 600, Tanita Corporation, Tokyo, Japan). Height, weight, head circumference and body mass index (BMI, ie, weight/height ${ }^{2}$ ) were converted to Z-scores. ${ }^{17}$

\section{Pulmonary function testing and respiratory questionnaire}

All lung function measurements were carried out according to American Thoracic Society (ATS)/European Respiratory Society (ERS) standards ${ }^{18-21}$ by two experienced respiratory physiologists (LW and JK), who were masked to birth status. Spirometry, static lung volumes and diffusing capacity for carbon monoxide $\left(\mathrm{DL}_{\mathrm{CO}}\right)$ were measured using a Jaeger MasterScreen body plethysmograph (Jaeger v5.02, Würzburg, Germany). Doctordiagnosed asthma, medication use and current respiratory symptoms including wheeze were determined by parental response to a modified version of the ISAAC questionnaire. ${ }^{22}$

\section{Peak exercise test}

Participants performed a symptom-limited incremental peak exercise test on an electronically braked cycle ergometer (Lode Excalibur, MedGraphics, Minnesota, USA). Maximum voluntary ventilation (MVV) was estimated as $35 \times$ forced expiratory volume in $1 \mathrm{~s}\left(\mathrm{FEV}_{1}\right){ }^{23}$ Peak exercise values were averaged over the final $20 \mathrm{~s}$ of maximal work.

\section{Physical activity}

To measure physical activity objectively, participants wore an ActiGraph GT1M accelerometer (ActiGraph, Fort Walton Beach, Florida, USA) for seven consecutive days during waking hours. ${ }^{24}$ Accelerometers were given to participants during their first visit to the Institute of Child Health (ICH) and were programmed to begin recording the following morning. In accordance with a recent accelerometer calibration study which focused on UK children of similar age, the lower threshold of moderate intensity activity was set at 3600 counts $/ \mathrm{min} .^{24}$ Participants also completed a diary to document weekly activities including those not captured by the accelerometer (eg, swimming), and a $10 \mathrm{~cm}$ visual-analogue scale regarding exercise perception.

\section{Data management and analysis}

Codes regarding birth status were released after data collection and analysis of lung function and exercise tests had been completed. Neonatal data from the EPICure cohort ${ }^{16}$ were used to determine which children had had BPD, defined as those requiring supplemental oxygen at 36 weeks postmenstrual age (PMA). ${ }^{25}$

Statistical analyses were performed using Stata Version 8.0 (Stata Corporation, College Station, Texas, USA). Lung function results were expressed as Z-scores to adjust for height, sex and age. $^{26-28}$ Unpaired t tests with $95 \%$ CIs were used to test if population means differed significantly. Since all physical activity variables and oxygen saturation levels were skewed, $\log _{n}$ transformations were performed prior to analysis. To determine whether peak $\mathrm{VO}_{2}(\mathrm{ml} / \mathrm{min})$ was lower in EP children compared with controls after adjustment for body size, peakVO $\mathrm{VO}_{2}$ and weight were $\log _{n}$ transformed prior to analysis of covariance (ANCOVA) and multivariable regression analysis. $\log _{\mathrm{n}} \mathrm{VO}_{2}$ was set as the dependent variable, with birth status (ie, EP/control) the grouping variable. Identical analyses were performed for anaerobic threshold.

Given that several potential determinants were only relevant to survivors of EP birth, separate multivariable regression models were also developed for the EP and control groups (see OLS). Lung function and physical activity variables initially underwent univariable analysis to determine their inclusion in the multivariable model. GA, birth weight, BPD, supplemental oxygen at 40 weeks PMA, head circumference at test, dyspnoea on exercise, cough during exercise, current wheeze and asthma diagnosis were adjusted for in the multivariable model for EP

Table 1 Background characteristics

\begin{tabular}{|c|c|c|c|c|}
\hline Group & Extremely preterm (EP) $n=38$ & Controls $n=38$ & Mean difference (95\% CI) (EP-control) & p Value \\
\hline Females: n (\%) & $27(71 \%)$ & $23(61 \%)$ & $4(-11 \%$ to $30 \%)$ & 0.33 \\
\hline BPD n (\%) & $27(71 \%)$ & - & NA & NA \\
\hline GA (weeks) ${ }^{*}$ & $25.0(24.7-25.1) \dagger$ & $40.0(40.0-40.4) \dagger$ & NA & NA \\
\hline Birth weight $(\mathrm{g})$ & $740(107)$ & $3360(527)$ & NA & NA \\
\hline Age at test (years) & $11.1(0.4)$ & $11.0(0.5)$ & $0.1(-0.04$ to 0.4$)$ & 0.12 \\
\hline Height (cm) & $142.4(5.6)$ & $145.6(5.8)$ & $-3.2(-5.8$ to -0.6$)$ & 0.01 \\
\hline Height Z-score & $-0.3(0.8)$ & $0.3(0.8)$ & $-0.6(-1.0$ to -0.3$)$ & 0.001 \\
\hline Weight $(\mathrm{kg})$ & $36.8(8.5)$ & $39.2(6.7)$ & $-2.4(-5.9$ to 1.1$)$ & 0.17 \\
\hline Weight Z-score & $-0.1(1.0)$ & $0.4(0.9)$ & $-0.5(-1.0$ to -0.1$)$ & 0.02 \\
\hline BMI $\left(\mathrm{kg} / \mathrm{m}^{2}\right)$ & $18.0(3.1)$ & $18.4(2.4)$ & $-0.4(-1.7$ to 0.9$)$ & 0.53 \\
\hline BMI Z-score & $-0.004(1.3)$ & $0.36(0.9)$ & $-0.36(-0.9$ to 0.1$)$ & 0.15 \\
\hline $\mathrm{HC}(\mathrm{cm})$ & $52.5(1.7)$ & $54.0(1.6)$ & $-1.5(-2.6 ;-0.5)$ & 0.01 \\
\hline HC Z-score & $-1.3(1.3)$ & $-0.15(1.15)$ & $-1.15(-1.94$ to -0.40$)$ & 0.01 \\
\hline$\%$ Current asthma diagnosis & $32 \%$ & $16 \%$ & $16(-3 \%$ to $34 \%)$ & 0.10 \\
\hline
\end{tabular}

*Data are presented as median (IQR).

†Five EP children had a gestational age $<24$ completed weeks, 11 were $\geq 24$ and $<25$ weeks, and 22 were $\geq 25$ and $<26$ weeks.

Data are presented as mean (SD) unless otherwise stated.

$\mathrm{BMI}$, body mass index; BPD, bronchopulmonary dysplasia; GA, gestational age; $\mathrm{HC}$, head circumference; NA, not applicable. 
Table 2 Comparison of pulmonary function in extremely preterm and control children

\begin{tabular}{|c|c|c|c|c|}
\hline Group & Extremely preterm (EP) $n=38$ & Control $n=38$ & Mean difference (95\% CI) (EP-control) & p Value \\
\hline FEV $_{1}$ Z-score ${ }^{*}$ & $-1.64(1.32)$ & $0.10(0.90)$ & $-1.74(-2.25$ to -1.23$)$ & $<0.0001$ \\
\hline $\mathrm{FEF}_{25-75}$ Z-score* & $-2.10(1.3)$ & $-0.51(1.1)$ & $-1.59(-2.12$ to -1.00$)$ & $<0.0001$ \\
\hline FVC Z-score* & $-0.89(1.1)$ & $0.25(0.97)$ & $-1.14(-1.6$ to -0.67$)$ & $<0.0001$ \\
\hline $\mathrm{DL}_{\mathrm{co}}$ Z-score $\dagger$ & $-1.1(1.0)$ & $-0.16(1.0)$ & $-0.94(-1.41$ to -0.43$)$ & $<0.001$ \\
\hline RV Z-score† & $1.31(1.10)$ & $0.73(0.83)$ & $0.58(0.10$ to 1.10$)$ & 0.02 \\
\hline TLC Z-score† & $0.23(0.44)$ & $0.41(0.52)$ & $-0.18(-0.43$ to 0.06$)$ & 0.14 \\
\hline
\end{tabular}

Data presented as mean (SD).

*Stanojevic et al (2008). ${ }^{28}$

tRosenthal et al (1993). ${ }^{27}$

$\neq$ Rosenthal (2008). ${ }^{26}$

$\mathrm{DL}_{\mathrm{CO}}$, diffusing capacity for carbon monoxide; $\mathrm{FEF}_{25-75}$, forced midexpiratory flow rate; FEV , forced expiratory volume in $1 \mathrm{~s}$; FVC, forced vital capacity KCO, diffusing capacity for carbon monoxide corrected for alveolar volume; RV, residual volume; TLC, total lung capacity.

children. The model developed for controls also trialled dyspnoea on exercise, cough during exercise, current wheeze and asthma diagnosis. Significance levels were set at $\mathrm{p}<0.05$.

\section{RESULTS \\ Participants}

Eighty-three children (64\% female, $43 \mathrm{EP}$, of whom $28(65 \%)$ had prior BPD) participated in this study. Thirty-four (89\%) EP children received surfactant as neonates, $25(66 \%)$ received antenatal steroids and 23 (61\%) received systemic postnatal steroids over a median 21 days (IOR 14-30). One EP child was too short $(<120 \mathrm{~cm})$ for the cycle ergometer and six children ( 3 males, 4 EP) did not fulfil the set criteria for a peak exercise test due to submaximal effort, their and results were therefore excluded. This left comparative data in $38 \mathrm{EP}$ children $(71 \%$ with prior $\mathrm{BPD})$, and 38 controls. Success rates for exercise testing were similar in girls (94\%) and boys (87\%). Table 1 summarises background characteristics for those with successful exercise tests.

The groups were well matched for sex and age at test. Those born EP were significantly shorter and had lower weight, height and head circumference at test than full-term controls. There were no differences at the time of test in height, weight, BMI or head circumference when comparing EP children with and without BPD. Height and weight Z-scores for the entire EP school cohort (mean (SD): -0.4 (1.0) and -0.4 (1.3), respectively) and the proportion of females tested in school (64\%) were comparable with the EP subgroup undergoing exercise testing, as were neonatal characteristics (proportion of EP children with BPD, GA and birth weight (table 1). FEV 1 Z-scores for the entire EP school cohort (mean (SD):-1.4 (1.2)) were also similar to those in the subgroup recruited for exercise testing $\left(-1.6(1.3)\right.$ ) (table 2). ${ }^{29}$

\section{Lung function}

Pulmonary function results are summarised in table 2. Lung function was significantly impaired in those born EP, as shown by lower Z-scores for $\mathrm{FEV}_{1}$, forced midexpiratory flow rate $\left(\mathrm{FEF}_{25-75}\right)$, forced vital capacity (FVC), $\mathrm{DL}_{\mathrm{CO}}$ and carbon monoxide transfer coefficient $\left(\mathrm{K}_{\mathrm{CO}}\right)$, with higher Z-scores for residual volume (RV) and the RV/TLC (total lung capacity) ratio. EP children with prior BPD had a significantly lower TLC Z-score (mean difference $(95 \% \mathrm{CI})(-0.36(-0.68$ to -0.03$)), \mathrm{FEV}_{1} \mathrm{Z}$ score $(-1.0(-1.9$ to -0.09$))$ and FVC Z-score $(-0.82(-1.13$ to $-0.31)$ ), when compared with EP children without BPD.

\section{Peak exercise performance}

Baseline and peak exercise results are summarised in table 3 . Five EP children and two control children (all with current asthma) received a bronchodilator prior to exercise. At baseline, EP children had significantly lower tidal volumes ( $\mathrm{Vts}$ ), higher breathing frequency and were using more of their ventilatory reserve compared with controls. At peak exercise, children born EP had significantly lower oxygen consumption (peakVO $\mathrm{V}_{2}$ ), anaerobic threshold (AT), minute ventilation $\left(\mathrm{V}_{\mathrm{E}}\right)$, Vt and oxygen pulse $\left(\mathrm{VO}_{2} /\right.$ heart beat), and $\sim 20 \%$ lower workload compared with controls. The EP group also displayed greater peak breathing frequencies and used more of their ventilatory reserve $\left(\mathrm{V}_{\mathrm{E}} / \mathrm{MVV}\right)$. In contrast, there were minimal differences in the remaining outcome variables between the groups (table 3 ). No child desaturated below $96 \%$. Compared with controls, the EP group had significantly smaller changes in $\mathrm{VO}_{2}, \mathrm{Vt}, \mathrm{V}_{\mathrm{E}}$ and oxygen pulse, and larger changes in $\mathrm{V}_{\mathrm{E}} / \mathrm{MVV}$ between baseline and peak exercise (table E1 OLS). There were no significant differences between those with and without BPD at peak exercise.

ANCOVA revealed that EP children had a significant deficit in peakVO 2 after differences in body size were accounted for. The corresponding multivariable regression equation is shown below:

$\log _{\mathrm{n}}$ peakVO $\mathrm{V}_{2}(\mathrm{ml} / \mathrm{min})=5.48-0.18($ birth status $)+0.52$

$$
\left(\log _{\mathrm{n}} \text { weight }(\mathrm{kg})\right)
$$

$\mathrm{R}^{2}=0.44 ; \mathrm{p}<0.0001$, where birth status $=1$ for $E \mathrm{P}, 0$ for controls.

In absolute terms this equates to a mean $(95 \% \mathrm{CI})$ deficit in peakVO $\mathrm{Vf}_{2} \sim 253 \mathrm{ml} / \mathrm{min}(-359$ to -147$)$ for EP children after adjusting for body size.

The same analysis for AT revealed a mean $(95 \% \mathrm{CI})$ deficit of $\sim 67 \mathrm{ml} / \mathrm{min}(-134$ to -2$)$ for EP children (see OLS for regression equation).

Multivariable regression for children born EP showed that sex, $\log _{\mathrm{n}}$-transformed weight, height, BMI and head circumference at time of test were all significant independent predictors of $\log _{\mathrm{n}}$ peakVO $(\mathrm{ml} / \mathrm{min})\left(\mathrm{R}^{2}=0.57\right)$. In brief, body weight, male sex and head circumference were all positively associated with peak $\mathrm{VO}_{2}$, whereas height and BMI were negatively associated (see table E2 OLS). Lung function and physical activity variables, along with GA, birth weight, BPD, supplemental oxygen requirement at 40 weeks PMA, dyspnoea on exercise, cough during exercise, current wheeze and asthma diagnosis failed to reach significance. For controls, only $\log _{\mathrm{n}}$-adjusted weight and sex reached statistical significance.

Although $\mathrm{FEV}_{1}$ and $\mathrm{DL}_{\mathrm{CO}} \mathrm{Z}$-scores did not reach significance within the regression model, there were significant, albeit weak, correlations between peakVO $\mathrm{VO}_{2}$ and both $\mathrm{FEV}_{1}\left(\mathrm{R}^{2}=0.10\right)$ and $\mathrm{DL}_{\mathrm{CO}} \mathrm{Z}$-scores $\left(\mathrm{R}^{2}=0.22\right)$ (figures 1 and 2 ). 
Table 3 Baseline and maximal exercise performance in extremely preterm and control children

\begin{tabular}{|c|c|c|c|c|c|c|}
\hline & \multicolumn{3}{|l|}{ Baseline } & \multicolumn{3}{|l|}{ Peak exercise } \\
\hline & $\begin{array}{l}\text { Extremely } \\
\text { preterm (EP) }\end{array}$ & Control & $\begin{array}{l}\text { Mean difference } \\
\text { (95\% CI) (EP-control) }\end{array}$ & $\begin{array}{l}\text { Extremely } \\
\text { preterm (EP) }\end{array}$ & Control & $\begin{array}{l}\text { Mean difference } \\
\text { (95\% CI) (EP-control) }\end{array}$ \\
\hline $\mathrm{n}$ & 38 & 38 & & 38 & 38 & \\
\hline $\mathrm{VO}_{2}(\mathrm{ml} / \mathrm{min})$ & $251(75)$ & $256(47)$ & $-5(-24$ to 34$)$ & $1293(271)$ & $1590(263)$ & $-297(-419 \text { to }-175)^{* * *}$ \\
\hline Heart rate (beats/min) & $93.5(12.6)$ & $94.0(16.0)$ & $-0.5(-6.7$ to 6.5$)$ & $185(15)$ & $190(12)$ & $-5(-11.3$ to 1.2$)$ \\
\hline $\mathrm{SpO}_{2}(\%) \dagger$ & $99(98-99)$ & $99(99-100)$ & $-0.3(-0.9$ to 0.2$)$ & $99(98-100)$ & $99(99-100)$ & $-0.2(-0.6$ to 0.6$)$ \\
\hline Respiratory exchange ratio $\left(\mathrm{VCO}_{2} \mathrm{NO}_{2}\right)$ & $0.87(0.07)$ & $0.88(0.06)$ & $-0.01(-0.04$ to 0.02$)$ & $1.13(0.06)$ & $1.12(0.05)$ & $0.01(-0.01$ to 0.04$)$ \\
\hline Breathing frequency (breaths/min) & $19.0(4.9)$ & $16.7(4.0)$ & $2.3(0.2 \text { to } 4.3)^{*}$ & $57.2(16)$ & $50.9(11.0)$ & $6.3(0.1 \text { to } 12.6)^{*}$ \\
\hline $\mathrm{Vt} / \mathrm{kg}(\mathrm{ml} / \mathrm{kg})$ & $11.2(3.6)$ & $12.2(3.7)$ & $1.0(-2.7$ to 0.64$)$ & $24.2(8.0)$ & $28.3(5.1)$ & $-4.1(-7.2 \text { to }-1.0)^{* *}$ \\
\hline $\mathrm{V}_{\mathrm{E}} / \mathrm{kg}(\mathrm{l} / \mathrm{min} / \mathrm{kg})$ & $0.2(0.05)$ & $0.2(0.04)$ & $0.01(-0.01$ to 0.03$)$ & $1.31(0.36)$ & $1.42(0.31)$ & $-0.11(-0.26$ to 0.05$)$ \\
\hline $\mathrm{V}_{\mathrm{E}} / \mathrm{MVV}$ & $0.13(0.04)$ & $0.10(0.02)$ & 0.03 (0.01 to; 0.05) & $0.83(0.22)$ & $0.70(0.14)$ & $0.13(0.04 \text { to } 0.21)^{* *}$ \\
\hline Oxygen pulse (ml/beat) & $2.7(0.8)$ & $2.7(0.7)$ & $0.03(-0.4$ to 0.4$)$ & $7.0(1.5)$ & $8.4(1.5)$ & $-1.4(-2.1 \text { to }-0.7)^{* *}$ \\
\hline $\mathrm{PETCO}_{2}(\mathrm{mmHg})$ & $37.7(2.4)$ & $37.3(2.3)$ & $0.4(-0.7$ to 1.5$)$ & $35.9(4.9)$ & $37.0(3.8)$ & $-1.1(-3.1$ to 1.0$)$ \\
\hline $\mathrm{PETO}_{2}(\mathrm{mmHg})$ & $106.0(4.4)$ & $107.0(3.9)$ & $-1.0(-3.0$ to 0.8$)$ & $115.4(4.9)$ & $114.9(4.4)$ & $0.5(-1.7$ to 2.5$)$ \\
\hline $\mathrm{EqCO}_{2}$ & $30.0(2.4)$ & $30.5(2.8)$ & $-0.5(-1.7$ to 0.7$)$ & $32.1(4.3)$ & $30.7(3.1)$ & $1.4(-0.30$ to 3.10$)$ \\
\hline $\mathrm{EqO}_{2}$ & $34.6(4.2)$ & $34.7(4.1)$ & $-0.1(-2.0$ to 1.8$)$ & $36.3(5.3)$ & $34.4(4.1)$ & $1.9(-0.26$ to 4.10$)$ \\
\hline Systolic blood pressure (mmHg) & $97.1(10.7)$ & $99.0(8.8)$ & $-1.9(-8.0$ to 4.3$)$ & $127.4(14.2)$ & $127.6(17.6)$ & $-0.2(-10.0$ to 9.6$)$ \\
\hline Diastolic blood pressure (mmHg) & $57.0(10.6)$ & $60(7.5)$ & $-3.0(-8.5$ to 3.0$)$ & $60.5(10.5)$ & $63.5(8.2)$ & $-3.0(-8.8$ to 2.8$)$ \\
\hline Work/kg & - & - & - & $2.70(0.63)$ & $3.11(0.50)$ & $-0.41(-0.67 \text { to }-0.15)^{* *}$ \\
\hline Anaerobic threshold $\mathrm{VO}_{2}(\mathrm{ml} / \mathrm{min})$ & & & & $760(172)$ & $858(180)$ & $-98(-178$ to 18$)$ \\
\hline Exercise time (min) & - & - & - & $14.4(1.9)$ & $15.3(2.0)$ & $-0.9(-1.7$ to 0.04$)$ \\
\hline
\end{tabular}

†Data are presented as median (IQR) and log transformed prior to comparisons.

Data are presented as mean (SD)

${ }^{*} \mathrm{p}<0.05 * * \mathrm{p}<0.01 * * * \mathrm{p}<0.001$.

All baseline variables are averaged over the final $20 \mathrm{~s}$ of rest.

All peak exercise variables are averaged over the final $20 \mathrm{~s}$ of maximal completed work, except for anaerobic threshold and time.

$\mathrm{EqCO}_{2}$, ventilatory equivalent for carbon dioxide; $\mathrm{EqO}_{2}$, ventilatory equivalent for oxygen; $\mathrm{PETCO}_{2}$, end-tidal partial pressure of carbon dioxide; $\mathrm{PETO}$, end-tidal partial pressure of oxygen; $\mathrm{SpO}$, peripheral oxygen saturation; $\mathrm{V}_{\mathrm{E}}$, minute ventilation; $\mathrm{V}_{\mathrm{E}} / \mathrm{MVV}$, ventilatory reserve; $\mathrm{VO}_{2}$, oxygen consumption; $\mathrm{Vt}_{\text {, tidal volume. }}$

\section{Physical activity}

All participants were provided with accelerometers, but acceptable data (see OLS for criteria) were only achieved in 61 (73\%) children (31 EP, 30 controls). Despite marked differences in peak $\mathrm{VO}_{2}$, there were no differences in any physical activity measures between groups, and only a very weak within-subject correlation $\left(\mathrm{R}^{2}=0.07 ; \mathrm{p}<0.03\right)$ between peakVO 2 and activity counts/min (figure 3). Additional activities recorded in the diary (but not by the accelerometer) included a median swimming time of 90 min (range $30-450$ ) in 28 children (16 EP), a median cycling time of $40 \mathrm{~min}(10-265)$ in 29 children (14 EP), a mean horse-riding time of $225 \mathrm{~min}$ in two EP children and a mean of 45 min trampolining in a further two children (1 EP).

On a self-assessment visual-analogue scale, the EP group had a lower exercise capability and reported more difficulty breathing during exercise when compared with their peers (table 4). There
Figure 1 Peak oxygen consumption $(\mathrm{ml} / \mathrm{kg} / \mathrm{min})$ versus forced expiratory volume in $1 \mathrm{~s}\left(\mathrm{FEV}_{1}\right)$ Z-score in controls and extremely preterm (EP) children categorised according to bronchopulmonary dysplasia (BPD) status. $\mathrm{O}=$ controls, $\mathbf{\square}=\mathrm{EP}$ without BPD; $\boldsymbol{\Delta}=\mathrm{EP}$ with BPD.

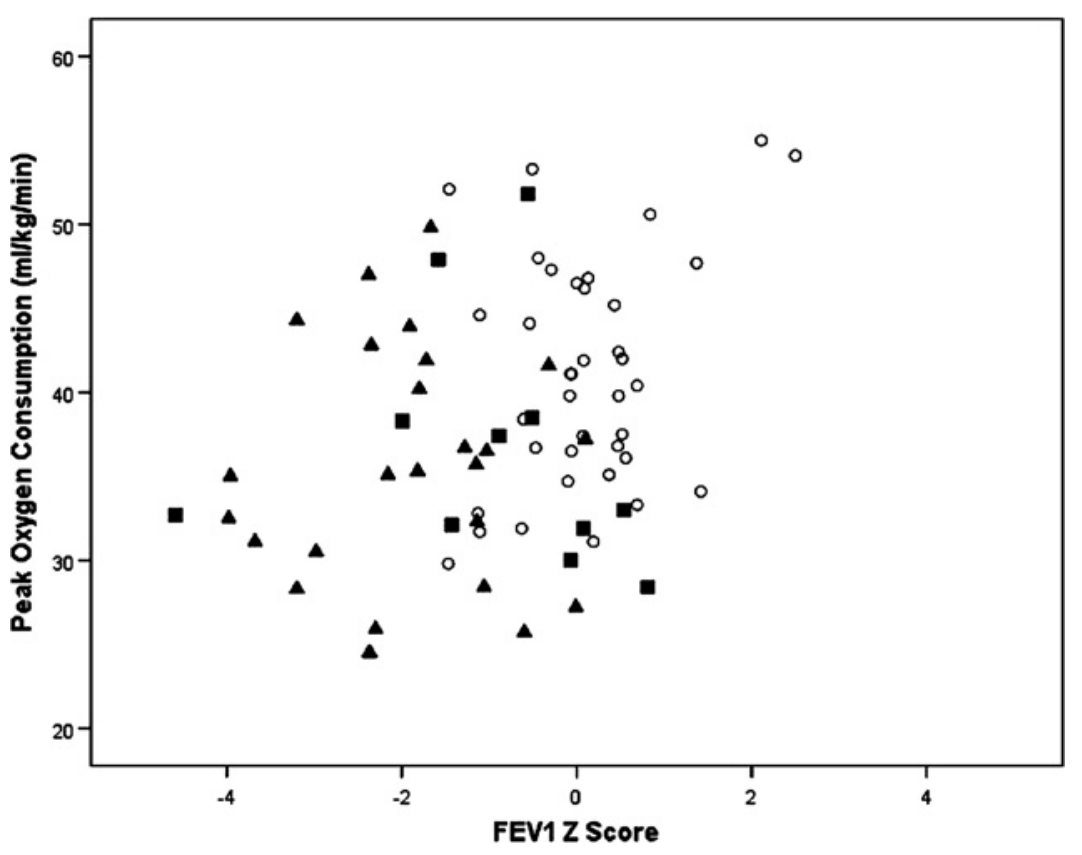


Figure 2 Peak oxygen consumption $(\mathrm{ml} / \mathrm{kg} / \mathrm{min})$ versus diffusing capacity for carbon monoxide $\left(\mathrm{DL}_{\mathrm{co}}\right) \mathrm{Z}$-score in controls and extremely preterm (EP) children categorised according to bronchopulmonary dysplasia (BPD) status. $\mathrm{O}=$ controls, $\mathbf{\square}=\mathrm{EP}$ without $\mathrm{BPD} ; \boldsymbol{\Delta}=\mathrm{EP}$ with $\mathrm{BPD}$.

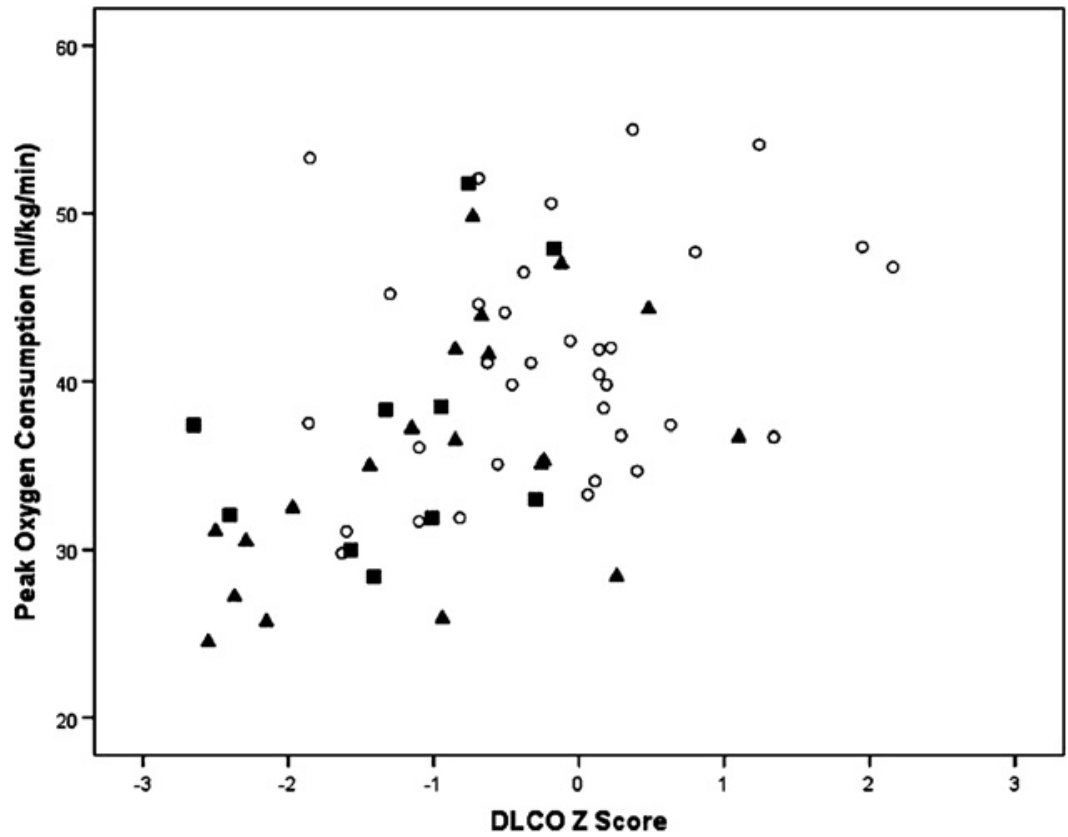

were no associations between any of the exercise perception responses and objective or diary-reported measures of physical activity.

\section{DISCUSSION}

Compared with age-matched controls, EP children had significantly lower peakVO $\mathrm{V}_{2}$. Moreover, EP children had a lower logadjusted AT and achieved a significantly lower peak workload. Children born EP also adopted an unusual breathing pattern during peak exercise, characterised by relatively shallow breathing and higher breathing frequencies. Despite this exaggerated tachypnoea, these children did not exceed their predicted MVV or have a ventilatory limitation to exercise in the absence of EIB. These differences were not associated with differences in overall physical activity or time spent in moderate to vigorous physical activity (MVPA) between the two groups, although EP children perceived themselves as less able to undertake activity than their classmates.

Since children only attended for exercise tests if they were sufficiently coordinated to perform technically acceptable lung function at school, it is possible that these results may underestimate the true degree of exercise limitation within the entire EPICure cohort. ${ }^{16}$ However, as presented earlier, the EP subgroup who underwent exercise testing appeared to be representative of the entire EP school cohort with successful spirometry recordings.

There is some evidence that females born preterm have better outcomes than males during infancy and childhood, ${ }^{16}$ whereas by late adolescence males have been reported to have fewer respiratory symptoms. ${ }^{13}$ In this study, no significant differences in lung function or physical activity were detected according to sex, although the power to detect such differences was limited.
Figure 3 Peak oxygen consumption $(\mathrm{ml} / \mathrm{kg} / \mathrm{min})$ versus physical activity counts (counts/min) in controls and extremely preterm (EP) children categorised according to bronchopulmonary dysplasia (BPD) status. $\bigcirc=$ controls, $\boldsymbol{\square}=\mathrm{EP}$ without BPD; $\boldsymbol{\Delta}=\mathrm{EP}$ with BPD.

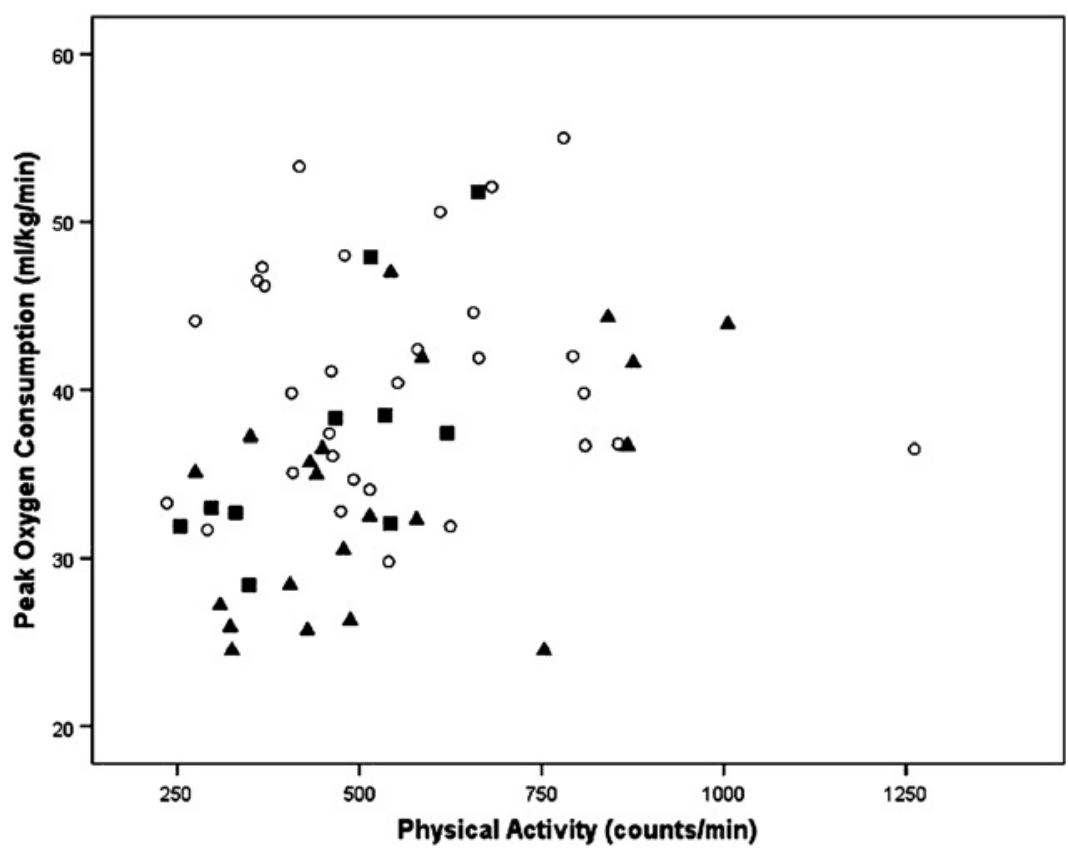


Table 4 Physical activity data in extremely preterm and control children

\begin{tabular}{|c|c|c|c|c|}
\hline & $\begin{array}{l}\text { Extremely preterm } \\
\text { (EP) } n=31\end{array}$ & Control $n=\mathbf{3 0}$ & $\begin{array}{l}\text { Mean Difference } \\
\text { (95\% CI) (EP-control) }\end{array}$ & p Value \\
\hline \multicolumn{5}{|l|}{ Accelerometer } \\
\hline Duration of daily recording (min) & $735(709-756)$ & $743(704-764)$ & $-8(-35$ to 19$)$ & 0.57 \\
\hline Activity counts/min (counts/min) & $478(417-542)$ & $503(459-623)$ & $45(-150$ to 59$)$ & 0.38 \\
\hline MVPA (min/day) & $9.0(4.3-11.9)$ & $11.0(7.0 ; 17.5)$ & $-2(-11.5$ to 1.4$)$ & 0.12 \\
\hline \multicolumn{5}{|l|}{ Exercise perception questionnaire } \\
\hline $\begin{array}{l}02 \text { When exercising, do you find it difficult to breathe? } \\
(0 \mathrm{~cm} \text { : very difficult, } 10 \mathrm{~cm} \text { : not at all) }\end{array}$ & $5.7(4.5-6.9)$ & $7.9(6.6-9.3)$ & $-2.2(-4.0$ to -0.5$)$ & 0.01 \\
\hline $\begin{array}{l}03 \text { When exercising, do you notice that you have } \\
\text { a cough? }(0 \mathrm{~cm} \text { : all the time, } 10 \mathrm{~cm} \text { : never) }\end{array}$ & $8.2(7.3-9.2)$ & $9.0(8.3-9.8)$ & $-0.8(-2.1$ to 0.6$)$ & 0.24 \\
\hline $\begin{array}{l}\text { 04 When exercising, do you feel wheezy or have } \\
\text { tightness in your chest? }(0 \mathrm{~cm} \text { : all the time, } 10 \mathrm{~cm} \text { : never) }\end{array}$ & $6.8(5.4-8.0)$ & $7.8(6.4-9.3)$ & $-1.0(-3.0$ to 0.9$)$ & 0.28 \\
\hline
\end{tabular}

Data presented as median (IQR) and log transformed prior to comparison.

Responses to exercise perception questions were completed on a $10 \mathrm{~cm}$ visual-analogue scale, with $0 \mathrm{~cm}$ representing the worst outcome and $10 \mathrm{~cm}$ the best outcome. MVPA, moderate to vigorous physical activity.

Strengths of this study include the fact that investigators were masked to birth status and prior medical history until data collection and analyses were complete, strict quality control was imposed for all physiological and anthropometric measurements, ${ }^{19}$ and results were compared with those from a prospectively studied, age-matched control group. Furthermore, this is one of the larger investigations of objectively measured exercise capacity in EP children born in recent years, and the first to collect objective physical activity data in this population; the benefits of which have been highlighted recently. ${ }^{30}$

Though the current study showed clear deficits in peakVO for children born EP, there is contradictory evidence regarding exercise capacity among survivors of preterm birth, with a similar number of studies showing no difference in peakVO ${ }_{2}^{4-6813}$ to those reporting a deficit. 791112 The disparity within the literature is difficult to reconcile given the variation in exercise protocols and sample sizes, differing definitions of BPD and the heterogeneous nature of neonatal treatments across study groups.

Multivariable allometric regression revealed that several factors contributed to the observed deficit in peakVO $\mathrm{among}_{2}$ children. Log-adjusted weight, height and BMI were all found to be significant predictors of peakVO $\mathrm{V}_{2}$. These findings point to a reduced muscle mass among $\mathrm{EP}$ children and may have contributed to the earlier onset of metabolic acidosis (ie, AT) and hence lower workload achieved. Although we were unable to measure fat-free mass, the EP group was significantly lighter and shorter than controls. A dose-response relationship has previously been observed between lean body mass and peak $\mathrm{VO}_{2}$, supporting the contention that a reduction in force-producing tissue may result in reduced peakVO $2 .{ }^{31}$ Considering these results and the neonatal course of EP survivors, the presence of some peripheral muscle weakness cannot be discounted.

Head circumference (a marker of brain weight and development) was also found to be a significant covariate in the regression model for EP children, though not for controls. A small head circumference has previously been identified as a risk factor for poor mechanical efficiency ${ }^{32}$ and reduced motor ability. ${ }^{33}$ Moreover, reduced head circumference may reflect impaired development of the central nervous system, both prenatally and in later life among children born EP. ${ }^{34}$

The deficits in $\mathrm{FEV}_{1}$ and $\mathrm{DL}_{\mathrm{CO}}$ suggest that persistent airway obstruction and impaired gas transfer subsequent to disrupted alveolarisation and impaired pulmonary microvascular development among EP children ${ }^{8}$ may have also contributed to the reduction in peakVO $\mathrm{VO}_{2}$. The presence of any anaemia due to haemoglobin deficiency could have contributed to the deficit in $\mathrm{DL}_{\mathrm{CO}}$ and in turn, peakVO , but was not measured in this study. EIB should also be considered, with a higher prevalence reported for children born preterm. ${ }^{8}$ Interestingly, EP children perceived themselves less capable of exercise than their peers and reported more difficulty breathing during everyday exercise.

The fact that ventilation was augmented during exercise primarily by breathing frequency rather than $\mathrm{Vt}$ in children born EP indicates an elevated deadspace to tidal volume ratio. Any marked degree of ventilation-perfusion mismatch as a result of this unusual ventilatory response seems unlikely as there was no significant reduction in oxygen saturation during exercise. Nevertheless, the reduced diffusing capacity among EP children at rest indicates that the pulmonary vascular bed may have been less able to accommodate increased cardiac output during peak exercise. In support of these findings, previous studies of EP-born children and adults have also found deficits in $\mathrm{DL}_{\mathrm{CO}},{ }^{13} 3536$ with others reporting low Vt and elevated respiratory rates during maximal exercise in children born preterm. ${ }^{89}$ Blood pressure was similar between groups at rest and peak exercise, though this does not exclude a circulatory limitation.

While we can only speculate about the cause of observed differences in ventilatory adaptations to exercise, they may reflect early changes in lung pathology and/or chemoreceptor setting following EP delivery. Given the elevated RV and RV/ TLC ratio, degree of airway obstruction and resistive load found amongst the EP children, some degree of dynamic hyperinflation is likely to occur during exercise, ${ }^{37}$ with an associated increase in elastic load. ${ }^{9}$ Rather than elevate Vt during exercise (and in turn raise elastic and resistive loads further), increased ventilatory demands may be achieved more efficiently in such subjects by increasing breathing frequency more than usual. Alternatively, these findings may reflect long-term effects from the delayed postnatal resetting of peripheral chemoreceptors in infants with $\mathrm{BPD}^{38}$ or some fundamental alteration in oxygen consumption following EP birth. Although the markedly elevated breathing frequency did not lead to hypocapnia, subtle differences in peripheral chemoreceptor function in EP-born children may contribute to an altered regulation of ventilation during exercise. 
While physical activity habits and degree of deconditioning among children are important considerations when assessing peak $\mathrm{VO}_{2}$, we found only weak associations in this study, with no differences between EP and controls. Both groups undertook considerably less physical activity than current recommendations of at least $60 \mathrm{~min}$ MVPA/day. ${ }^{39}$ This is in keeping with other recent UK studies of similar aged healthy children. ${ }^{24} 38$ Overall activity levels were somewhat higher (but remained similar between groups) if activities including swimming, cycling and horse-riding were considered, yet still remained worryingly low. The majority of children in this study were probably performing insufficient activity to realise any improvements in cardiorespiratory fitness. While both groups would benefit from a physical conditioning programme, the effects are likely to be more marked in those born EP given their deficit in peak $\mathrm{VO}_{2}$.

\section{CONCLUSION}

PeakVO 2 in childhood survivors of EP birth is lower than in agematched controls. This impairment was significantly associated with poorer growth and development. The EP group also displayed ventilatory adaptations during peak exercise distinct from controls, employing greater breathing frequencies to compensate for low Vts. Importantly, physical activity could not explain the difference in exercise performance between groups. Considering that EP children did not exceed their predicted MVV or display significant oxygen desaturation on exertion, this study suggests that exercise is likely to be safe for the majority of children born EP and should be encouraged to promote cardiopulmonary fitness.

Acknowledgements The EPICure Investigators Group: K Costeloe (London), ES Draper (Leicester) EM Hennessy (London), N Marlow (Nottingham; Chief Investigator), J Stocks (London).

Developmental Panel: Paediatricians: Joseph Fawke, Susan Thomas and Victoria Rowell; Psychologists: Sam Johnson, Rebecca Smith, Rebecca Trikic; Study Administrator: Heather Palmer.

The EPICure Study Group comprises the paediatricians in 276 maternity units across the UK and Ireland who contributed the original patients to the study, whose invaluable help we acknowledge in the establishment of these studies. The Investigator group was responsible for the funding and the overall design of studies at 11 years; patients were recruited by Joseph Fawke, Susan Thomas and Victoria Rowell; LW and JK performed the data collection, validation and analysis, supervised by SL and JS. D0 undertook the exercise testing supervised by GD. We acknowledge the support provided by Andy Ness and Callum Mattocks, ALSPAC team, Bristol with regard to activity monitoring; Rif Chaudry for the design of the exercise questionnaire and would also like to thank Donald Urquhart for his intellectual contribution in the development of this manuscript. We would particularly like to thank the children and families who traveled often large distances to participate in this study.

Funding The Medical Research Council.

Competing interests None

Ethics approval This study was conducted with the approval of the multicentre research ethics committee.

Patient consent Obtained.

Provenance and peer review Not commissioned; externally peer reviewed.

\section{REFERENCES}

1. Wilson-Costello D, Friedman H, Minich $\mathrm{N}$, et al. Improved survival rates with increased neurodevelopmental disability for extremely low birth weight infants in the 1990s. Pediatrics 2005;115:997-1003.

2. Bhandari A, Panitch HB. Pulmonary outcomes in bronchopulmonary dysplasia. Semin Perinatol 2006;30:219-26.

3. Coalson JC. Pathology of bronchopulmonary dysplasia. Semin Perinatol 2006;30:179-84

4. Bader D, Ramos AD, Lew CD, et al. Childhood sequelae of infant lung disease: exercise and pulmonary function abnormalities after bronchopulmonary dysplasia. J Pediatr 1987;110:693-9.
5. Baraldi $\mathbf{E}$, Zanconato $\mathrm{S}$, Zorzi $\mathrm{C}$, et al. Exercise performance in very low birth weight children at the age of 7-12 years. Eur J Pediatr 1991;150:713-16.

6. Jacob SV, Lands LC, Coates AL, et al. Exercise ability in survivors of severe bronchopulmonary dysplasia. Am J Respir Crit Care Med 1997:155:1925-9.

7. Kilbride HW, Gelatt MC, Sabath RJ. Pulmonary function and exercise capacity for ELBW survivors in preadolescence: effect of neonatal chronic lung disease. J Pediatr 2003;143:488-93.

8. Kriemler S, Keller H, Saigal S, et al. Aerobic and lung performance in premature children with and without chronic lung disease of prematurity. Clin J Sport Med 2005; 15:349-55

9. Pianosi PT, Fisk M. Cardiopulmonary exercise performance in prematurely born children. Pediatr Res 2000:47:653-8.

10. Sabath RJ, Kilbride HW, Walsh VM. Peak exercise capacity and pulmonary function of children born extremely premature. Ped Exerc Sci 1999;11:255-6.

11. Santuz P, Baraldi E, Zaramella P, et al. Factors limiting exercise performance in long-term survivors of bronchopulmonary dysplasia. Am J Respir Crit Care Med 1995;152:1284-9.

12. Smith LJ, van Aspersen $P$. McKay KO, et al. Reduced exercise capacity in children born very preterm. Pediatrics 2008;122:e287-93.

13. Vrijlandt EJ, Gerritsen J, Boezen HM, et al. Lung function and exercise capacity in young adults born prematurely. Am J Respir Crit Care Med 2006:173:890-6.

14. Hebestreit $\mathbf{H}$, Bar-Or O. Exercise and the child born prematurely. Sports Med 2001:31:591-9.

15. Pelkonen AS, Hakulinen AL, Turpeinen M. Bronchial lability and responsiveness in school children born very preterm. Am J Respir Crit Care Med 1997;156:1178-84.

16. Costeloe K, Hennessy E, Gibson AT, et al. The EPICure study: outcomes to discharge from hospital for infants born at the threshold of viability. Pediatrics 2000;106:659-71.

17. Cole TJ, Freeman JV, Preece MA. British 1990 growth reference centiles for weight height, body mass index and head circumference fitted by maximum penalized likelihood. Stat Med 1998;17:407-29.

18. American Thoracic Society. Single-breath carbon monoxide diffusing capacity (transfer factor). Recommendations for a standard technique-1995 update. Am J Respir Crit Care Med 1995;152:2185-98.

19. Kirkby J, Welsh L, Lum S, et al. The EPICure study: comparison of pediatric spirometry in community and laboratory settings. Pediatr Pulmonol 2008;43:1233-41.

20. Miller MR, Hankinson J, Brusasco V, et al. Standardisation of spirometry. Eur Respir J 2005;26:319-38

21. Wanger J, Clausen JL, Coates A, et al. Standardisation of the measurement of lung volumes. Eur Respir J 2005;26:511-22.

22. Asher MI, Keil U, Anderson HR, et al. International Study of Asthma and Allergies in Childhood (ISAAC): rationale and methods. Eur Respir J 1995;8:483-91.

23. European Respiratory Society. Clinical exercise testing with reference to lung diseases: indications, standardization and interpretation strategies. ERS Task Force on Standardization of Clinical Exercise Testing. European Respiratory Society. Eur Respir $J$ 1997:10:2662-89.

24. Riddoch CJ, Mattocks C, Deere K, et al. Objective measurement of levels and patterns of physical activity. Arch Dis Child 2007:92:963-9.

25. Jobe AH, Bancalari E. Bronchopulmonary dysplasia. Am J Respir Crit Care Med 2001;163:1723-9.

26. Rosenthal M. Annual assessment spirometry, plethysmography, and gas transfer in cystic fibrosis: do they predict death or transplantation. Pediatr Pulmonol 2008:43:945-52.

27. Rosenthal $\mathbf{M}$, Bain $\mathrm{SH}$, Cramer D, et al. Lung function in white children aged 4 to 19 years: I-spirometry. Thorax 1993;48:794-802.

28. Stanojevic S, Wade A, Stocks J, et al. Reference ranges for spirometry across all ages: a new approach. Am J Respir Crit Care Med 2008;177:253-60.

29. Fawkes J. The EPICure study: respiratory outcomes at 11 years. Arch Dis Child 2008:93(Suppl I):A42

30. Reilly JJ, Penpraze V, Hislop J, et al. Objective measurement of physical activity and sedentary behaviour: review with new data. Arch Dis Child 2008;93:614-19.

31. American Thoracic Society. ATS/ACCP Statement on cardiopulmonary exercise testing. Am J Respir Crit Care Med 2003;167:211-77.

32. Hebestreit $\mathbf{H}$, Dietz $\mathrm{S}$, Hiermer A. Body coordination and mechanical efficiency in children born prematurely. Ped Exerc Sci 1999:11:34.

33. Hutton JL, Pharoah PO, Cooke RW, et al. Differential effects of preterm birth and small gestational age on cognitive and motor development. Arch Dis Child Fetal Neonatal Ed 1997;76:F75-81.

34. Falk B, Eliakim A, Dotan R, et al. Birth weight and physical ability in 5- to 8-yr-old healthy children born prematurely. Med Sci Sports Exerc 1997;29:1124-30.

35. Hakulinen AL, Jarvenpaa AL, Turpeinen M, et al. Diffusing capacity of the lung in school-aged children born very preterm, with and without bronchopulmonary dysplasia. Pediatr Pulmonol 1996;21:353-60.

36. Korhonen P, Laitinen J, Hyodynmaa E, et al. Respiratory outcome in school-aged, very-low-birth-weight children in the surfactant era. Acta Paediatr 2004;93:316-21.

37. Macklem PT. Circulatory effects of expiratory flow-limited exercise, dynamic hyperinflation and expiratory muscle pressure. Eur Respir Rev 2006;15:80-4.

38. Caldner NA, Williams BA, Smyth J, et al. Absence of respiratory chemoreflex responses to mild hypoxia in infants who have suffered bronchopulmonary dysplasia. Pediatr Res 1994:35:677-81.

39. Strong WB, Malina RM, Blimkie CJ, et al. Evidence based physical activity for schoolage youth. J Pediatr 2005;146:732-7. 